Please do not remove this page

RMIT

UNIVERSITY

\title{
Cities are hotspots for threatened species
}

Ives, Christopher; Lentini, Pia; Threlfall, Caragh; Ikin, Karen; Shanahan, Danielle; Garrard, Georgia; Bekessy, Sarah

https://researchrepository.rmit.edu.au/esploro/outputs/9921862428801341/filesAndLinks?institution=61RMIT_INST\&index=null

Ives, C., Lentini, P., Threlfall, C., Ikin, K., Shanahan, D., Garrard, G., Bekessy, S., Fuller, R., Mumaw, L., Rayner, L., Rowe, R., Valentine, L., \& Kendal, D. (2016). Cities are hotspots for threatened species. Global Ecology and Biogeography, 25(1), 117-126. https://doi.org/10.1111/geb.12404

Document Version: Accepted Manuscript

Published Version: https://doi.org/10.1111/geb.12404

Repository homepage: https://researchrepository.rmit.edu.au

(C) 2015 John Wiley and Sons Ltd

Downloaded On 2023/04/26 20:21:23 +1000

Please do not remove this page 
Thank you for downloading this document from the RMIT Research Repository.

The RMIT Research Repository is an open access database showcasing the research outputs of RMIT University researchers.

RMIT Research Repository: http://researchbank.rmit.edu.au/

\section{Citation:}

Ives, C, Lentini, P, Threlfall, C, Ikin, K, Shanahan, D, Garrard, G, Bekessy, S, Fuller, R, Mumaw, L, Rayner, L, Rowe, R, Valentine, L and Kendal, D 2016, 'Cities are hotspots for threatened species', Global Ecology and Biogeography, vol. 25, no. 1, pp. 117-126.

See this record in the RMIT Research Repository at:

https://researchbank.rmit.edu.au/view/rmit:36138

Version: Accepted Manuscript

\section{Copyright Statement:}

(C) 2015 John Wiley and Sons Ltd

\section{Link to Published Version:}

http://dx.doi.org/10.1111/geb.12404 
3 Christopher D. Ives ${ }^{1_{+}}$, Pia E. Lentini ${ }^{2 *}$, Caragh G. Threlfall ${ }^{3}$, Karen Ikin $^{4}$, Danielle F. Shanahan ${ }^{5}$,

4 Georgia E. Garrard ${ }^{1}$, Sarah A. Bekessy ${ }^{1}$, Richard A. Fuller ${ }^{5}$, Laura Mumaw ${ }^{1}$, Laura Rayner ${ }^{4}$, Ross

$5 \quad$ Rowe $^{4,6,7}$, Leonie E. Valentine ${ }^{8}$, Dave Kendal ${ }^{9}$

6

$7 \quad{ }^{1}$ School of Global, Urban and Social Studies, RMIT University.

$8 \quad{ }^{2}$ School of BioSciences, University of Melbourne

$9 \quad{ }^{3}$ School of Ecosystem and Forest Sciences, University of Melbourne

$10 \quad{ }^{4}$ Fenner School of Environment and Society, Australian National University

$11 \quad{ }^{5}$ School of Biological Sciences, University of Queensland

$12 \quad{ }^{6}$ Australian Government Department of the Environment

$13 \quad{ }^{7}$ National Environmental Research Program, Landscapes and Policy Research Hub, University of

14 Tasmania

$15{ }^{8}$ School of Plant Biology, The University of Western Australia.

$16 \quad{ }^{9}$ Australian Research Centre for Urban Ecology

$17{ }^{*}$ These authors contributed equally to this work.

$18+$ Current address: Faculty of Sustainability, Leuphana University, Lüneburg Germany.

19 chris.ives@leuphana.de

21 Keywords: Australia, biodiversity, conservation policy, threatened species, urbanization, species 22 distributions

23 Running title: The importance of cities for threatened species.

24 Corresponding author: Christopher Ives

25 Word counts: Abstract 296; Main body 4,118; References 1,158 
Aim

Although urbanisation impacts many species, there is little information on the patterns of threatened species occurrences in urban relative to non-urban areas. By assessing the extent of threatened species distributions across all Australian cities, we aim to investigate the currently under-utilised opportunity cities present to national biodiversity conservation.

Location

Australian mainland, Tasmania and offshore islands.

Methods

We assessed the distributions of Australia's 1,643 terrestrial threatened species and the extent to which they overlapped with 99 cities (of $>10,000$ people), with all non-urban areas, and with simulated 'dummy' cities which covered the same area and bioregion as the true cities but were non-urban. We analysed differences between animals and plants, and examined variability within these groups using species accumulation modelling. Threatened species richness of true versus dummy cities was analysed using generalised linear mixed-effects models.

Results

Australian cities support substantially more nationally threatened animal and plant species than all other non-urban areas on a unit-area basis. Thirty percent of threatened species were found to occur

49 in cities. Distribution patterns differed between plants and animals: threatened animals were generally distributed across multiple cities, while more individual plant species were found in each

51 city with a greater proportion of their distributions occurring in urban areas. Individual cities tended 
53 dummy cities demonstrated that, even after accounting for factors such as net primary productivity

54 and distance to the coast, cities still consistently supported a greater number of threatened species.

55

56 Main conclusions

57 This research highlights that Australian cities are important for threatened species conservation, and

58 that the species assemblages of individual cities are relatively distinct. National conservation policy

59 should recognise that cities play an integral role when planning for and managing threatened 60 species. 


\section{Introduction}

Threatened species can be found in cities all over the world. Twenty-two percent of the known occurrences of endangered plants in the USA fall within the 40 largest cities (Schwartz et al., 2002), and in an analysis of 54 cities Aronson et al. (2014) found that nearly a third are known to contain globally threatened birds. Indeed, the probability of a species being listed on the IUCN Red List increases with the percentage of its range that is urbanised (Mcdonald et al., 2008). The reasons for this are becoming well understood: cities are often located in areas of high biological diversity (Luck, 2007), and urbanisation is a significant and expanding land use change that leads to habitat loss and fragmentation (Seto et al., 2012). While the impacts of urbanisation on biodiversity are undeniable, this may also make cities especially important for achieving conservation outcomes. However, little is known about the relative importance of cities for conserving different kinds of organisms.

Urban areas occupy $<0.5 \%$ of the Earth's total land area (Schneider et al., 2009), yet some threatened species are highly reliant on urban environments. For example, in the United Kingdom, the song thrush Turdus philomelos, a declining species of national conservation concern, occurs at densities more than three times higher in urban habitats than in the surrounding rural environment (Mason, 2000). The endangered Nielsen Park She-oak (Allocasuarina portuensis) also occurs exclusively within the metropolitan area of greater Sydney. Despite examples such as these, the designation of protected areas remote from human disturbance remains the dominant conservation paradigm worldwide (Miller \& Hobbs, 2002). We have known for a long time that such wilderness thinking does not reflect ecological reality (Williams, 1980; Cronon, 1995). Yet conservation decision-making continues to implicitly, and sometimes explicitly, exclude urban environments from conservation investment (e.g. Sanderson et al., 2002; Mittermeier et al., 2003), as the negative pressures associated with urban development are seen to render urban habitats as 'lost causes’ from 
a biodiversity perspective (Cavin, 2013). By ignoring urban areas, important conservation opportunities are potentially missed.

On the Australian continent more than 1,600 species are considered threatened with extinction (Walsh et al., 2013). Australian environmental policies and legislation are similar to those of other biodiversity loss (Dales, 2011; McCauley et al., 2013).

The aim of this study is to assess the extent to which threatened species are reliant on conservation within cities. To explore this, we use the continent of Australia, which has very high endemic biodiversity (Chapman, 2009), as a case example, and investigate how the geographic distributions of species of national conservation concern overlap with urban areas. Specifically we measure how restricted threatened species' geographic ranges are to cities, and whether this is different for plants 
112 versus animals. Finally, we explore the potential contribution that individual cities can make to

113 biodiversity conservation by examining how the composition of threatened species varies in 114 different cities across the continent.

\section{Methods}

\subsection{Threatened species and city data}

118 All 1,643 species (1,215 plants and 428 animals) that are considered to be of 'national 119 environmental significance' under Australia's EPBC Act were included in our analyses. This includes nationally-listed threatened species, native migratory species listed under international conventions or agreements, and marine species that use terrestrial areas for nesting (Commonwealth of Australia, 2014a). We hereafter refer to all of these species as 'threatened species'. The listing criteria and categories used under the EPBC Act are adapted from those used to list species under the IUCN Red List of Threatened Species (Walsh et al., 2013), with the main difference being the absence of a 'near threatened' category from the EPBC Act making the list more conservative (Commonwealth of Australia, 2014a). The majority of these species were from the flowering plant class Magnoliopsida (857 species) followed by lilies (Liliopsida, 289 species), birds (181 species), mammals (84 species), and reptiles (50 species).

Polygons representing the modelled distribution of each species were sourced from the Australian Department of the Environment’s ‘Environment Resources Information Network’ (Commonwealth of Australia, 2014b). The Australian Government uses these data to inform management and policy decisions and to undertake preliminary assessments of whether proposed developments or land use changes trigger targeted assessment and approval under the EPBC Act. The polygons were modelled from observation records, ecological data and research information provided from a range of Australian government, industry and non-government organisations, in addition to national-scale environmental data. For migratory species, distributions refer only to breeding sites, sites of 
significance, or known locations rather than the entire range of the species. The polygons are not intended to be definitive maps of species occurrence, and generalisations made in the modelling process preclude detailed analyses of species distributions at fine scales. However, a reasonable level of spatial certainty is possible through classification of the polygons by the likelihood of species occurrence. For our analyses, only polygons where species are 'known to occur' (restricted to preferred habitat near observation records) and 'likely to occur' (preferred habitat within species range) were used. Polygons indicating where species 'may occur' (areas within environmental envelope or geographic region) were excluded. Polygons were projected to Geocentric Datum of Australia 1994 Australian Albers, and clipped to a shapefile representing terrestrial areas (the Australian mainland, Tasmania, and offshore territorial islands).

A layer representing the urban areas of Australia was derived from Australian Bureau of Statistics data (Section of State Ranges classification based on Statistical Area 1 polygons; Australian Bureau of Statistics, 2011a). This is a standard categorisation of land in Australia, used by government and non-government agencies. According to the dataset, land was classified as of "urban character” if: (i) the urban 'Mesh Block' (the smallest census unit) population is $\geq 45 \%$ of the total population of the Statistical Area 1 polygon and dwelling density $\geq 45$ dwellings per sq km; or (ii) the population density is $\geq 100$ persons per sq $\mathrm{km}$ and dwelling density $\geq 50$ dwellings per sq $\mathrm{km}$; or (iii) the population density is $\geq 200$ persons per sq km (Australian Bureau of Statistics, 2011b, p19). Only urban polygons with populations $>10,000$ people were selected (hereafter referred to as 'cities' for simplicity), thereby excluding the smallest settlements. Following our criteria, the 99 cities in Australia cover $17,420 \mathrm{~km}^{2}$ (0.23\% of terrestrial land mass), and range in size from $10.5 \mathrm{~km}^{2}$ for Nelson Bay, New South Wales, to $2597.4 \mathrm{~km}^{2}$ for Melbourne, Victoria (mean $=175.3 \mathrm{~km}^{2}$, median $=50.0 \mathrm{~km}^{2}, \mathrm{SD}=420.2 \mathrm{~km}^{2}$ ). Although designated as 'urban' in character, the scale at which these areas were classified meant that they contained a range of land covers including built and natural lands. 
Using ArcMap (v10.2, ESRI Redlands CA USA), we identified areas where the city polygons intersected with threatened species distribution polygons. From this, we calculated the proportion of each species' distribution that was urban and created a threatened species list for each city. To analyse the unique contribution of each city to the total assemblage of species located in urban areas, presence/absence species accumulation curves were generated using the 'specaccum'

171 function in the ‘vegan’ package in R (R Core Team 2014, vers 3.1.0). We also generated a pairwise Jaccard dissimilarity matrix for the presence and absence of plant and animal species per city and carried out a hierarchical cluster analysis (using the 'average' linkage method and the 'hclust' function) to assess differences in community composition between cities. We then mapped mean dissimilarity values for each of the cities to help visualise patterns of beta diversity across the continent.

We converted the polygons representing threatened species to $1 \mathrm{~km}^{2}$-resolution binary rasters using the 'rasterize' function in R's 'raster' package (vers 2.2-31). Raster cells were given a value of 1 if the centre of the cell overlapped with the associated polygon, or 0 if there was no overlap. We calculated the number of threatened species that were known or likely to occur in each cell by summing the values across all of the threatened species rasters.

As a conservative comparative analysis, we repeated the processes outlined above using only those polygons that represented where species were 'known' to occur. As the difference between these analyses was minimal (see Appendix S1) we consequently present only the results from the combined 'known' and 'likely' distributions here, as this includes the larger complement of species. 
To account for potentially confounding environmental variables that might influence the threatened

191 species richness of a city irrespective of urbanisation, for each of our 99 'true' cities we generated a paired 'dummy' city of equivalent area which was randomly positioned within the same bioregion (of which there are 89 across Australia). We then calculated both total threatened species richness of each true and dummy city, and the mean richness of the raster cells that comprised them. Both total and mean threatened species richness were analysed using mixed-effects regression models in the 'Ime4' package in R. Total threatened species richness was fitted as a generalised linear mixedeffects model against a Poisson distribution using a log link with the 'glmer' function, and mean threatened species richness as a linear mixed-effects model with the 'Imer' function. The models were fitted with five fixed predictor variables; (i) categorical city type (i.e. true v dummy), (ii) mean net primary productivity (NPP, calculated as the mean across the months of 2014 and downloaded as a 0.1 degree raster from NASA Earth Observations 2015), (iii) city area, (iv) distance from the coast (measured from the nearest city edge), and (v) latitude. Continuous variables were centred and scaled prior to the analysis. The bioregion in which the true or dummy city occurred was fitted as a random effect in both models. We also noted that protected areas made up a substantially smaller proportion of the landmass in the true cities (mean $=0.03 \pm 0.17 \mathrm{SD}$ ) than the dummy cities (mean $=0.12 \pm 0.33 \mathrm{SD}$ ), but because this was strongly correlated with city type it was not included in the models.

\section{Results}

\subsection{The distribution of threatened species in cities versus non-urban areas}

211 Of the 1,643 threatened species in our analysis, 503 (30\%) had distributions that intersected with 212 cities. This proportion differed for plants and animals, with 25\% of listed plants and 46\% of listed 213 animals having at least part of their distributions located in cities. Species distribution size varied considerably (many species had relatively small distributions and only a small number had very large distributions) but distribution size was not strongly correlated with the proportion of a species’ 
distribution located in cities (Spearman’s $\rho=0.33$ ). The distributions of animals (mean $=4.5$ million ha, median $=63,743 \mathrm{ha}$ ) tended to be much larger than those of plants (mean $=240,000$ ha, median $=13,463 \mathrm{ha}$ ). Threatened species richness was higher in coastal areas and around the edges of cities (Fig. 1).

There was substantial variation in the degree to which the distributions of threatened species included cities; species that were at least partially urban were found in an average of six cities ( \pm 11.8 SD). While some species were found in many cities (e.g. the eastern great egret Ardea modesta was found in 90 urban settlements), 258 threatened species (51\%) occurred in one urban settlement only (Fig 2a). The distributions of eight threatened species (all plants) entirely overlapped with cities, while 51 (10\%) of the 503 threatened species found in cities had >30\% of their distribution in urban areas (Fig. 2b). Patterns were quite different for threatened plants and animals; plants tended to be found in fewer cities (mean $=1.95 \pm 2.34 \mathrm{SD}$ ) than animals (mean $=$ $12.57 \pm 16.63 \mathrm{SD}$ ) and were thus more spatially restricted, but had a larger proportion of their distribution in cities (plant mean $=0.16 \pm 0.26 \mathrm{SD}$, animal mean $=0.04 \pm 0.08 \mathrm{SD}$, Fig. 2 ).

\subsection{The importance of cities for threatened species}

237 All 99 cities were known or likely to contain threatened animal species, and 88 cities (89\%) 238 contained threatened plant species or appropriate habitat (see Appendix S2 for city-specific details). 239 Cities coincided with the distributions of substantially more threatened species than all other non240 urban areas on a per-unit-area basis (Fig. 3). This was true for both animals and plants, with a very 241 high proportion of non-urban cells containing no threatened plant species. The mean threatened 
species richness for $1 \mathrm{~km}^{2}$ city cells was 10.04 ( $\left.\pm 3.79 \mathrm{SD}\right)$, and $2.72( \pm 2.88 \mathrm{SD})$ for non-urban cells.

$<$ Figure $3>$

On average, cities contained 32 threatened species ( \pm 25.5 SD). Sydney contained the most threatened species (124 species), but only a few (large) cities contained a high diversity of threatened species (Fig. 4a). This was especially pronounced for plants, with only $12 \%$ of cities containing >10 threatened plant species (see Fig. 4a).

Individual cities contained distinct sets of threatened species, and contributed unique species to the total urban assemblage with no evidence of an asymptote in the threatened species accumulation curves (Figure 4b). This differentiation among cities was driven primarily by threatened plants. Hierarchical cluster analysis supported this result, demonstrating that few cities had a similar threatened species composition (Appendix S3, Fig S3.1 and S3.2). The mean Jaccard dissimilarity score between cities for animals was 26.94 ( \pm 3.63 SD), with Kalgoorlie-Boulder supporting the most unique animal assemblage and Port Macquarie the least (Fig. S3.3). Plant communities were even more dissimilar between cities, with a mean Jaccard dissimilarity score of $26.76( \pm 3.76 \mathrm{SD})$; Kempsey supported the most unique plant assemblage while Taree's assemblage was most similar to other cities (Fig. S3.4).

$$
<\text { Figure } 4>
$$

Our comparison of true versus non-urban dummy cities reinforced the findings of our broader analysis. As noted above, total threatened species richness ranged from 2-124 for true cities (mean $=31.49, \pm 25.39 \mathrm{SD})$, and for dummies this range was 1-61 (mean $=12.12, \pm 11.07 \mathrm{SD})$. The mean 
threatened species richness of cells was $0.19-18.36$ for true cities (mean $=9.04, \pm 3.78 \mathrm{SD}$ ), and 0.02-14.07 for dummies (mean $=7.26, \pm 3.88 \mathrm{SD}$ ).

Regression modelling demonstrated that non-urban dummy cities had consistently lower total species richness $(-1.67, \pm 0.42 \mathrm{SE})$ than the true cities, even once potentially confounding factors had been accounted for (Fig. 5, see Appendix S4 for all coefficient estimates). Other factors which appeared to have strong effects on threatened species richness included net primary productivity, which was positively associated with mean cell richness $(1.15, \pm 0.34 \mathrm{SE})$, and distance from the coast, which had a negative effect on both mean cell richness $(-1.21, \pm 0.38 \mathrm{SE})$, and total richness (-0.72, \pm 0.09 SE, Fig. 5).

\section{$<$ Figure $5>$}

\section{Discussion}

\subsection{The importance of cities for conservation}

This is the first study to demonstrate at a continental scale that cities contain more threatened species per unit area than non-urban areas. Our analyses have shown that all Australian cities harbour or are likely to harbour threatened species, and 30\% of Australia's threatened species occur, or are likely to occur, in cities that cover only $0.23 \%$ of the total land area. The elevated importance of cities for threatened species richness remained evident even when accounting for other biogeographic factors that may affect species richness such as primary productivity, distance 290 from the coast, and latitude. This extends on the findings of Schwartz et al. (2002), who revealed that $22 \%$ of the occurrences of US endangered plant populations were located in the 40 largest metropolitan areas (comprising 8.4\% of the land area). We note, however, that these findings may be influenced by the fact that both Australian and US cities are relatively young on a global scale, 
and may be carrying extinction debts (Hahs et al., 2009). Further, it is likely that the regions defined

295 as 'urban' in this study contain a more heterogeneous composition of land covers than other studies 296 in the literature. We therefore reaffirm the need for clear definitions of urbanisation to be reported 297 in urban biodiversity studies, as has been called for by other scholars (McDonnell \& Hahs, 2013).

The greater richness of threatened species in cities compared with equivalent non-urban dummy 300 cities was more pronounced for total threatened species richness than for mean cell threatened 301 species richness (Fig. 5). This suggests that the assemblages of threatened species in cities vary more greatly across their area than equivalent non-urban areas. Cities are known to have high levels of landscape heterogeneity (Alberti, 2005), with patches of remnant habitat commonly interspersed with highly disturbed areas. This landscape configuration may favour a wider variety of threatened species, thus increasing beta diversity and contributing to the higher total threatened species richness observed in cities. This is plausible in Australia where native ecosystems commonly remain within and around cities and adjacent to other land uses (Bekessy et al., 2012; Newton et al., 2001).

\subsection{Spatial patterning of species distributions}

311 The composition of threatened species varies among cities (Fig. 4b, Appendix S3). This suggests 312 that the pattern identified by Aronson et al., (2014), whereby city biotas reflect regional species 313 pools, extends to threatened species. This trend may be especially pronounced in Australia given 314 that the cities included in our study cover a vast spatial area with huge variation in environmental 315 conditions. Patterns were different for plants and animals. Unique sets of threatened plants were 316 found in individual cities, while threatened animals tended to be found in multiple cities (Fig. 4b). 317 These results strongly suggest that all cities ought to be considered carefully in threatened species conservation and management. 
320 We found that a small subset of threatened species were highly restricted to cities, and that this 321 pattern was more pronounced for plants than it was for animals. Individual plant species were 322 usually found within few cities, however a large proportion of their distribution was contained 323 within those cities. In contrast, few animal species had a substantial share of their distributions 324 located in cities (Fig. 2b). Most threatened plants in our dataset have relatively small distributions, 325 and would be considered local endemics that are unique to certain bioclimatic regions of Australia. 326 For example, the fringed spider-orchid Caladenia thysanochila is an endangered species with a 327 small distribution, found entirely within a rapidly urbanizing region of Melbourne, Victoria 328 (Department of the Environment, 2014). In contrast, some animals had very large distributions, 329 occurring in 30 or more cities (Fig. 2a). This pattern of distribution for plants likely contributes to 330 our finding of higher total threatened species richness per city than mean cell threatened species 331 richness. Our finding that some threatened plants are found exclusively in urban environments is 332 similar to that for North American floras (Schwartz et al., 2002) and highlights that cities can be 333 important for the conservation of rare and unique plants.

\subsection{Implications for conservation policy and practice}

336 The disproportionate representation of threatened species in Australian cities identified in this study 337 suggests that practitioners should seek to identify and act upon conservation opportunities in urban 338 environments. It is important to note, though, that cities contain both threats and opportunities for 339 biodiversity conservation. The animals in our dataset included several nationally migrant and 340 nomadic species, such as the grey-headed flying-fox, Pteropus poliocephalus (Eby \& Collins, 1999) 341 and swift parrot, Lathamus discolor (Swift Parrot Recovery Team, 2001), that move across large 342 areas as food resources (e.g. nectar, fruit or blossoms) become seasonally available. Often these 343 resources are found in non-remnant, human-modified habitats. Indeed, Carnaby’s black cockatoo, 344 Calyptorhynchus latirostris, relies on an introduced pine plantation within the city of Perth for food, 345 despite the fact that this represents a comparatively small proportion of their range (Valentine et al., 
2014). Cities may be especially valuable to these kinds of species, as they can provide more stable resources throughout the year as a result of human planting selection and supplementary watering

348 (Parris \& Hazell, 2005; Williams et al., 2006). In contrast, other species rely on remnant patches of 349 vegetation for their survival, many of which are under threat or in a degraded condition. The fringed spider-orchid, for example, is unlikely to persist if its remaining historical habitat is developed for housing, and it occurrence may even represent an extinction debt given the amount of habitat remaining. Irrespective of whether threatened species are threatened by urbanisation or supported by urban conditions, this study highlights the need for conservation action in cities. Depending on the nature of conservation threats and opportunities, a suite of conservation tools should be employed, such as spatial planning of urban development (e.g. Bekessy et al., 2012), focussed recovery planning, and active management, restoration, and improvement of habitats (Hahs et al., 2009; Standish et al., 2012).

\subsection{Caveats and future research opportunities}

As with any spatial data compiled from multiple sources over a period of time, our species data may contain mapping errors. The most pertinent errors are those of commission and omission as a result of incomplete and unequal sampling effort. Few systematic biodiversity surveys have been conducted in Australia, yet those that have been done have often excluded urban areas (e.g. the regional forest agreement process; Slee, 2001). On the other hand, it is possible that ad-hoc databases may have an over-representation of urban records, as survey effort will arguably be greater in more populous areas. Ultimately, despite any inaccuracies, the results presented here are noteworthy since the datasets are those used by decision makers when assessing development 368 applications and generating species recovery plans. Nevertheless, while our conservative analysis 369 indicated that modelling assumptions did not having a large impact on our inference relating to the distribution of threatened species in cities, future research could explore the role of possible sampling biases further. 
373 Finally, we note that while presence of a population in a location does not indicate its fitness or 374 long-term viability in that location, it signals a potential conservation opportunity. In their 375 multidisciplinary review of 787 urban biodiversity conservation studies, Shwartz et al. (2014) found 376 only eight papers reported similar or improved levels of population viability of species of 377 conservation significance in urban areas compared to nearby greener environments. Yet they also 378 note that only three studies specifically set out to test this condition of viability, all of which 379 reported in the affirmative. From these results Shwartz et al. (2014) concluded that "the importance 380 of urban areas for general conservation is not convincingly supported by scientific research” (p. 43). 381 Nevertheless, we argue that even if threatened species experience lower levels of population 382 viability in urban environments, their overrepresentation in these areas makes cities even more 383 important for conservation management and planning, noting too that doing nothing may reduce 384 viability even further. We echo Shwartz et al.'s call for further research into the population 385 dynamics of significant species in cities as a way of shedding light on ecological mechanisms that 386 influence species persistence, as it can help determine which specific conservation actions are 387 required.

\section{Conclusion}

390 Using Australia as a case example, this study is the first to demonstrate at a continental scale that 391 cities contain disproportionately more threatened species than equivalent non-urban areas. Some 392 species (particularly plants) have a much greater proportion of their distribution within urban areas 393 than others, and all Australian cities are home to different suites of threatened species. These 394 findings highlight and reinforce the global importance of planning and managing urban landscapes 395 to conserve biodiversity (Secretariat of the Convention on Biological Diversity, 2012). We recommend that practitioners seriously consider the contribution that urban environments could 
397 make to national biodiversity conservation, and incorporate this information into species recovery 398 planning.

399

400 Acknowledgements

401 This research arose from a workshop held in Bungendore, NSW, in 2013, supported by the 402 Australian Research Council (ARC) Centre of Excellence for Environmental Decisions (CEED). 403 CDI, PEL, KI, DFS, SAB, RAF and LEV are supported by the Australian Government National 404 Environmental Research Program Environmental Decisions Hub (NERP ED). CDI, KI, GEG, SAB, 405 LM, LR and LEV are supported by the ARC CEED. GEG is supported by The Myer Foundation. 406 SAB and RAF are ARC Future Fellows. DFS is supported through ARC Discovery Grant 407 DP120102857. DK is supported by the Baker Foundation. CGT is supported through ARC Linkage 408 Grant LP110100686. We thank three anonymous reviewers and two editors whose comments 409 substantially improved this manuscript. 


\section{References}

Alberti, M. (2005) The Effects of Urban Patterns on Ecosystem Function. International Regional Science Review, 28, 168-192.

Aronson, M. F. J., La Sorte, F. A., Nilon, C. H., Katti, M., Goddard, M. A., Lepczyk, C. A., Warren, P. S., Williams, N. S. G., Cilliers, S., Clarkson, B., Dobbs, C., Dolan, R., Hedblom, M., Klotz, S., Kooijmans, J. L., Kuhn, I., MacGregor-Fors, I., McDonnell, M., Mortberg, U., Pysek, P., Siebert, S., Sushinsky, J., Werner, P. \& Winter, M. (2014). A global analysis of the impacts of urbanization on bird and plant diversity reveals key anthropogenic drivers. Proceedings of the Royal Society B, 281(20133330).

Australian Bureau of Statistics (2011a). Australian Statistical Geography Standard (ASGS). Available online: http://www.abs.gov.au/ausstats/abs@.nsf/Lookup/2901.0Chapter23102011 (Accessed 6 December 2014).

Australian Bureau of Statistics (2011b). Australian Statistical Geography Standard (ASGS): Volume 4 - Significant Urban Areas, Urban Centres and Localities, Section of State. Available online: http://www.ausstats.abs.gov.au/ausstats/subscriber.nsf/0/1080B7CB374FC771CA257A980013 D404/\$File/1270055004_july\%202011.pdf (Accessed 6 December 2014).

Bekessy, S. A., White, M., Gordon, A., Moilanen, A., Mccarthy, M. A., \& Wintle, B. A. (2012). Transparent planning for biodiversity and development in the urban fringe. Landscape and Urban Planning, 108, 140-149.

Cavin, J. S. (2013). Beyond prejudice: Conservation in the City. A case study from Switzerland. Biological Conservation, 166, 84-89.

Chapman, A. D. (2009). Numbers of Living Species in Australia and the World. A Report for the Australian Biological Resources Study September 2009. Australian Biodiversity Information Services, Toowoomba, Australia. URL http://www.environment.gov.au/node/13866 (Accessed 2 July 2015). 
Commonwealth of Australia, (2014a). Environment Protection and Biodiversity Conservation Act 1999. Available online: http://www.environment.gov.au/epbc (Accessed 6 December 2014).

Commonwealth of Australia, (2014b). Species of National Environmental Significance. Available online: http://www.environment.gov.au/science/erin/databases-maps/snes (Accessed 6 December 2014).

Cronon, W. J. (1995). The Trouble with Wilderness: Or, Getting Back to the Wrong Nature. In Uncommon Ground: Rethinking the human place in nature (Vol. 1, p. 7).

Dales, J. (2011). Death by a thousand cuts: Incorporating cumulative effects in Australia’s Environment Protection and Biodiversity Conservation Act. Pac. Rim L. \& Policy J., 20(1), $149-178$.

Department of the Environment, (2014). Policy statement for Melbourne urban development proposals needing consideration under Parts 7,8 and 9 of the EPBC Act. Department of the Environment, Australian Government, Canberra. Available online: http://www.environment.gov.au/resource/melbourne-urban-development-\%C2\%96-policystatement-environment-protection-and-biodiversity (Accessed 6 December 2014).

Department of Environment, (2013). Matters of national environmental significance, Significant impact guidelines 1.1, Environment Protection and Biodiversity Conservation Act 1999, Department of the Environment, Australian Government, Canberra. Available online: http://www.environment.gov.au/epbc/publications/significant-impact-guidelines-11-mattersnational-environmental-significance (Accessed 6 December 2014).

Eby, P., \& Collins, L. (1999). The distribution, abundance and vulnerability to population reduction of a nomadic nectarivore, the Grey-headed Flying-fox Pteropus poliocephalus in New South Wales, during a period of resource concentration. Australian Zoologist, 31(1), 240-253.

Hahs, A. K., McDonnell, M. J., McCarthy, M. A., Vesk, P. A., Corlett, R. T., Norton, B. A., Clemants, S. E., Duncan, R. P., Thompson, K., Schwartz, M. W. \& Williams, N. S. G. (2009). A global synthesis of plant extinction rates in urban areas. Ecology Letters, 12(11), 1165-73. 
Luck, G. W. (2007). A review of the relationships between human population density and biodiversity. Biological Reviews of the Cambridge Philosophical Society, 82(4), 607-45.

McDonnell, M.J. \& Hahs, A.K. (2013) The future of urban biodiversity research: Moving beyond the “low-hanging fruit.” Urban Ecosystems, 16, 397-409.

Mason, C. F. (2000). Thrushes now largely restricted to the built environment in eastern England. Diversity and Distributions, 6, 189-194.

McCauley, L. A., Jenkins, D. G., \& Quintana-Ascencio, P. F. (2013). Isolated Wetland Loss and Degradation Over Two Decades in an Increasingly Urbanized Landscape. Wetlands, 33(1), $117-127$.

Mcdonald, R. I., Kareiva, P., \& Forman, R. T. T. (2008). The implications of current and future urbanization for global protected areas and biodiversity conservation. Biological Conservation, 141(6), 1695-1703.

Miller, J. R., \& Hobbs, R. J. (2002). Conservation Where People Live and Work. Conservation Biology, 16(2), 330-337.

Mittermeier, R. a, Mittermeier, C. G., Brooks, T. M., Pilgrim, J. D., Konstant, W. R., da Fonseca, G. a B., \& Kormos, C. (2003). Wilderness and biodiversity conservation. Proceedings of the National Academy of Sciences of the United States of America, 100(18), 10309-10313.

NASA Earth Observations (2015). Net primary productivity (1 month - terra/modis), http://neo.sci.gsfc.nasa.gov/view.php?datasetId=MOD17A2_M_PSN (Accessed 2 July 2015).

Natural Resource Management Ministerial Council (2010). Australia’s Biodiversity Conservation Strategy 2010-2030, Australian Government, Department of Sustainability, Environment, Water, Population and Communities, Canberra

Newton PW, Baum S, Bhatia K et al (2001) Human settlements theme, Australia state of the environment report 2001. CSIRO Publishing, Canberra, Australia 
Parris, K. M., \& Hazell, D. L. (2005). Biotic effects of climate change in urban environments: The case of the grey-headed flying-fox (Pteropus poliocephalus) in Melbourne, Australia. Biological Conservation, 124(2), 267-276.

R Core Team (2014). R: A language and environment for statistical computing. R Foundation for Statistical Computing, Vienna, Austria. URL http://www.R-project.org/.

Sanderson, E. W., Jaiteh, M., Levy, M. a., Redford, K. H., Wannebo, A. V., \& Woolmer, G. (2002). The Human Footprint and the Last of the Wild. BioScience, 52(10), 891.

Schneider, A., Friedl, M.A. \& Potere, D. (2009) A new map of global urban extent from MODIS satellite data. Environmental Research Letters, 4, 044003.

Schwartz, M. W., Jurjavcic, N. L., \& Brien, J. M. O. (2002). Conservation’s Disenfranchised Urban Poor. BioScience, 52(7), 601-606.

Secretariat of the Convention on Biological Diversity. (2012). Cities and Biodiversity Outlook: Action and Policy. Montreal. URL: https://www.cbd.int/doc/health/cbo-action-policy-en.pdf (Accessed 2 July 2015).

Seto, K.C., Güneralp, B. \& Hutyra, L.R. (2012) Global forecasts of urban expansion to 2030 and direct impacts on biodiversity and carbon pools. Proceedings of the National Academy of Sciences of the United States of America, 109, 16083-8.

Shwartz, A., Turbé, A., Julliard, R., Simon, L., \& Prévot, A.-C. (2014). Outstanding challenges for urban conservation research and action. Global Environmental Change, 28, 39-49.

Slee, B., (2001). Resolving production-environment conflicts: the case of the regional forest agreement process in Australia. Forest Policy and Economics 3, 17-30.

Standish, R. J., Hobbs, R. J., \& Miller, J. R. (2012). Improving city life: options for ecological restoration in urban landscapes and how these might influence interactions between people and nature. Landscape Ecology. 28(6): 1213-1221.

Swift Parrot Recovery Team (2001) Swift Parrot (Lathamus discolor) Recovery Plan 2001-2005. Tasmanian Department of Primary Industries, Water and Environment. URL 
$513 \quad \underline{2005}$ (Accessed 2 July 2015).

514 Valentine, L.E., Fisher, R., Wilson, B.A., Sonneman, T., Stock, W.D., Fleming, P.A. and Hobbs, 515 R.J. (2014) Time since fire influences food resources for an endangered species, Carnaby’s $516 \quad$ cockatoo, in a fire-prone landscape. Biological Conservation, 175: 1-9.

517 Walsh, J.C., Watson, J.E.M., Bottrill, M.C., Joseph, L.N. \& Possingham, H.P. (2013) Trends and 518 biases in the listing and recovery planning for threatened species: an Australian case study. $519 \quad$ Oryx, 47, 1-10.

520 Williams, N. S. G., Mcdonnell, M. J., Phelan, G. K., Keim, L. D., \& Van Der Ree, R. (2006). Range 521 expansion due to urbanization: Increased food resources attract Grey-headed Flying-foxes 522 (Pteropus poliocephalus) to Melbourne. Austral Ecology, 31(2), 190-198.

523 Williams, R. (1980). Ideas of Nature. In Problems in Materialism and Culture. London: Verso. 


\section{Biosketch}

526 The authors of this study are Australian researchers with interests in urban ecological systems and 527 biodiversity conservation. Together, a wide range of disciplines is represented including ecology, 528 social science and environmental policy. This article is an output from a workshop funded by the 529 Australian Research Council Centre of Excellence for Environmental Decisions. Many of the 530 authors are affiliated with the Environmental Decisions Group (EDG): a network of conservation 531 researchers working on the science of effective decision making to better conserve biodiversity. 532 More details about EDG can be found at http://www.edg.org.au/ 


\section{Figure legends}

535 Figure 1. Threatened species richness across Australia, with darker colours representing greater 536 richness. Urban areas are outlined in black. Cities shown in greater detail in boxes are (a) Perth, (b) 537 Brisbane and (c) Melbourne.

Figure 2. Plots of (a) species ranked according to the number of cities in which they occur and (b) the proportion of their distributions that fall in cities. Species are ordered on the x-axes by their

541 rank, with the species occurring in the most cities, or with the greatest proportion of their 542 distribution as urban, assigned the rank of 1.

Figure 3. The proportion of $1 \mathrm{~km}^{2}$ cells in Australia, classified as either urban (white) or non-urban (grey) which support different numbers of threatened species. Data are presented for (a) all threatened species, (b) animals and (c) plants. Bars being skewed to the left of the plots indicates that a greater proportion of cells support fewer threatened species. Across Australia a small number of cells contained from 19 up to 32 threatened species, but the plot has been truncated at 18 along the $\mathrm{x}$-axis because bars were not visible when the proportion was $<0.005$.

Figure 4. Plots of (a) ranked and (b) cumulative richness of threatened species in cities. The lack of asymptote in the species accumulation curves (b) suggests that each city contributes different species to the overall pool of threatened species found in urban areas.

Figure 5. Model curves comparing cities and equivalent 'dummy cities' within bioregions for (a) total threatened species richness, and (b, c) mean $1 \mathrm{~km}^{2}$ richness of threatened species. Higher richness is consistently observed for cities, even once distance from the coast and net primary productivity are accounted for. 
$559 \quad$ Figure 1.
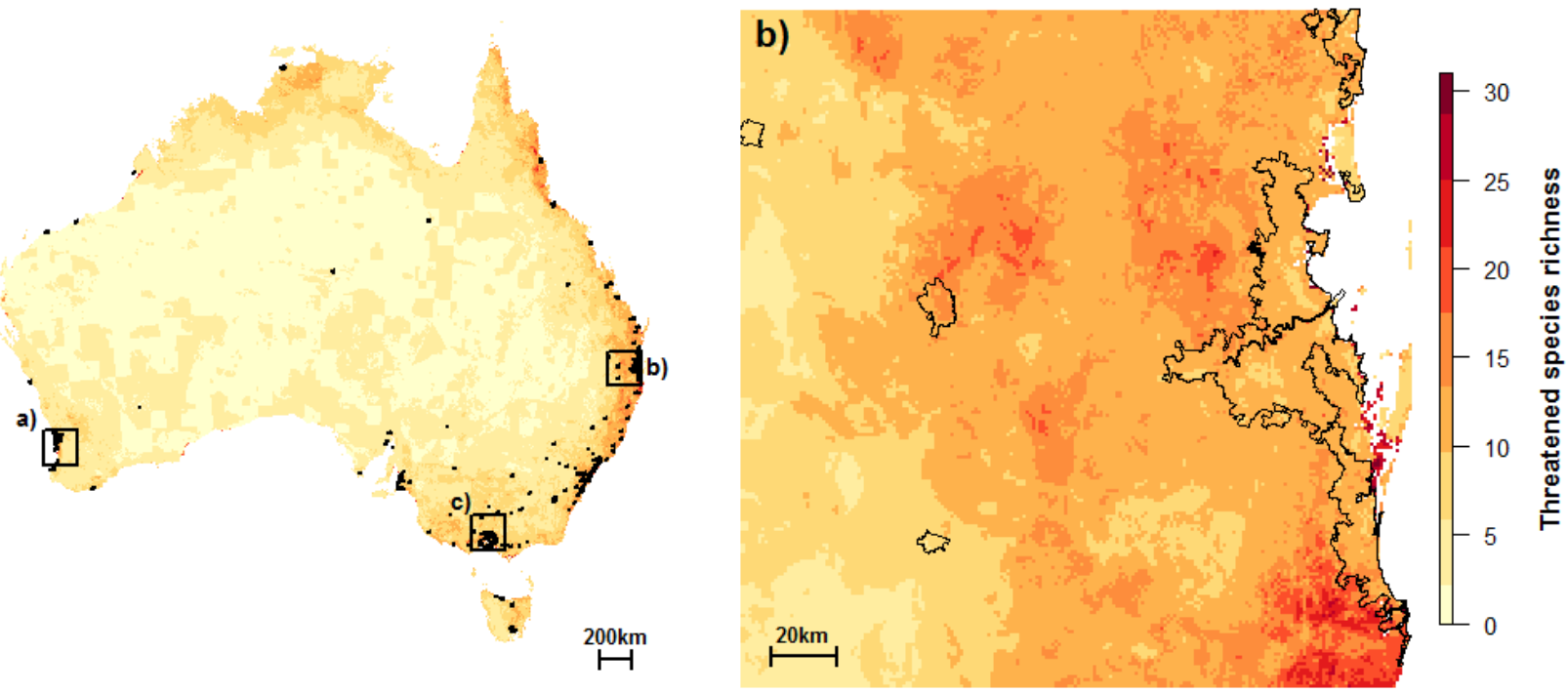

a)

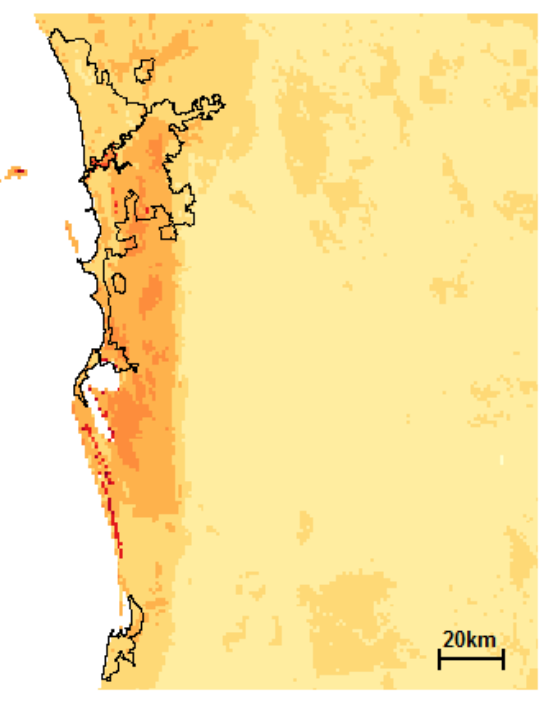

c) हm

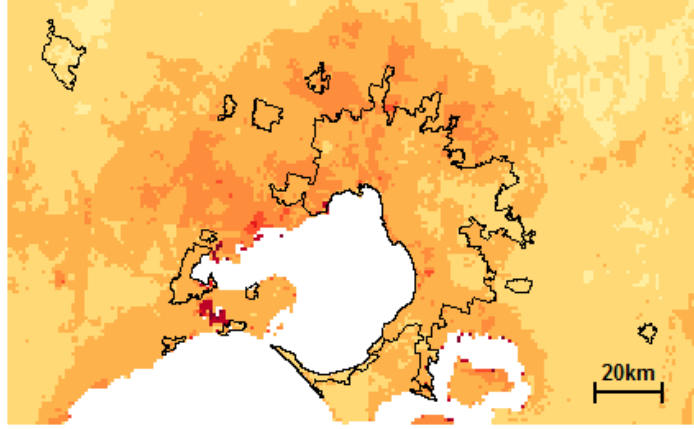


$561 \quad$ Figure 2.
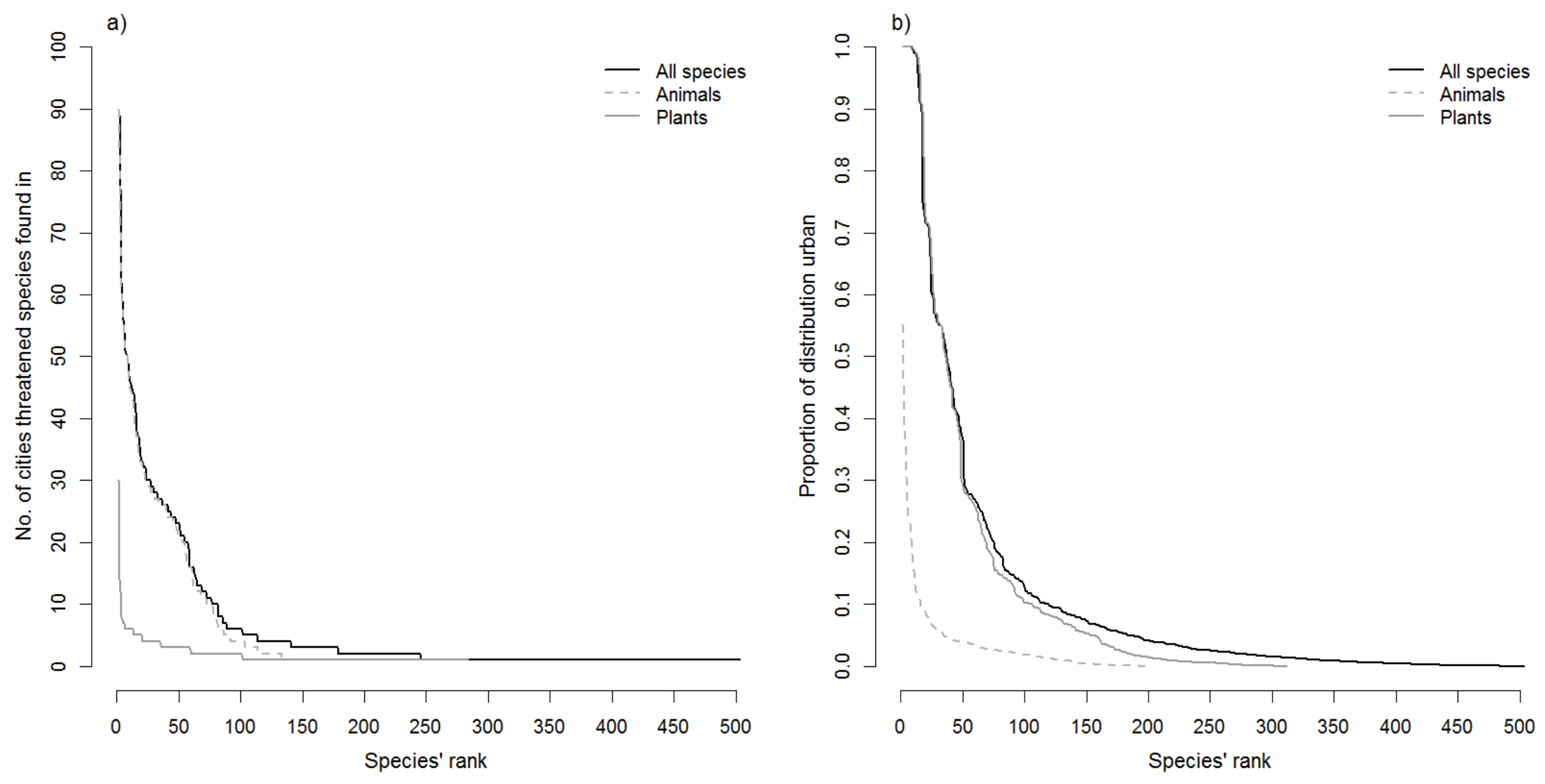
$563 \quad$ Figure 3.
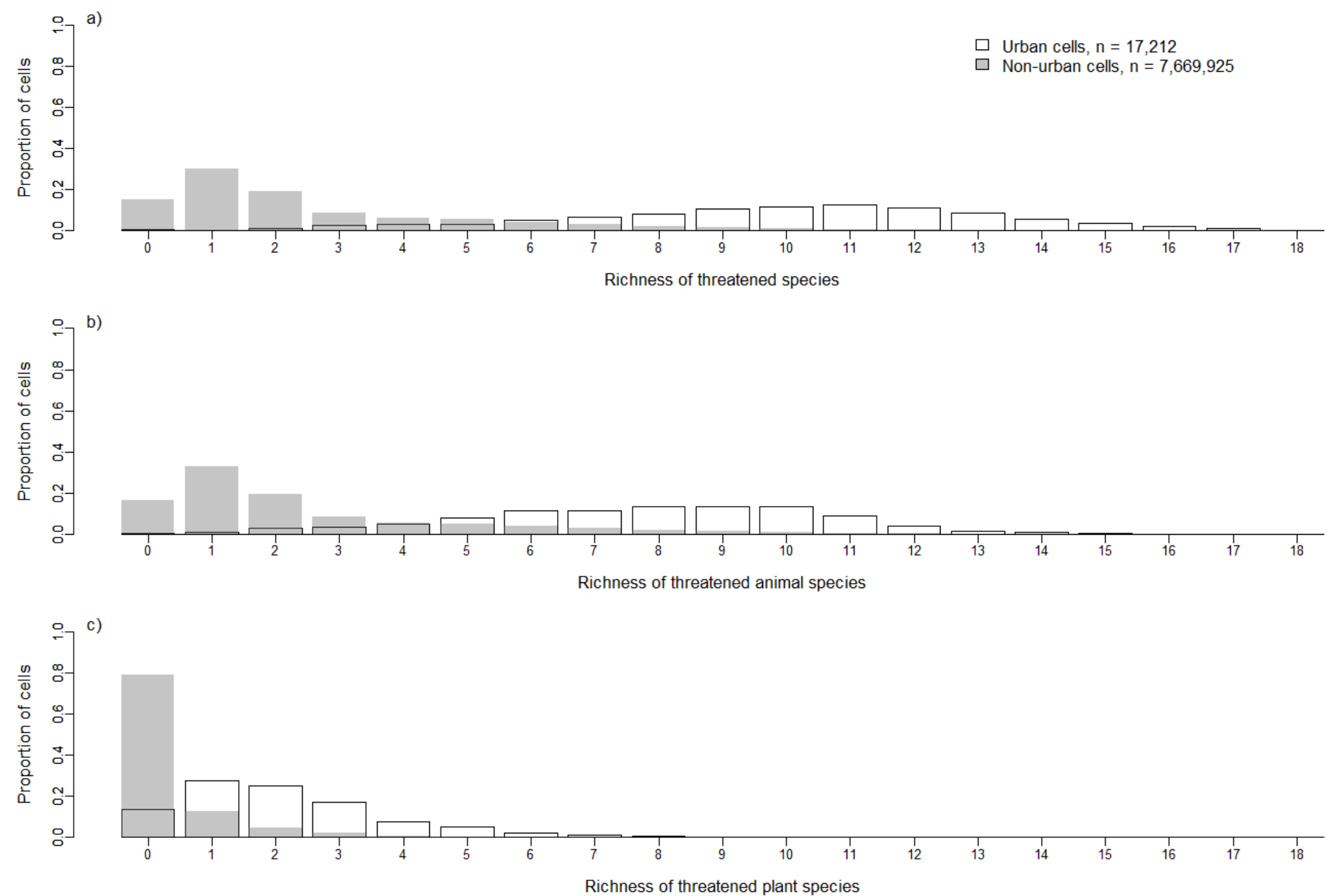

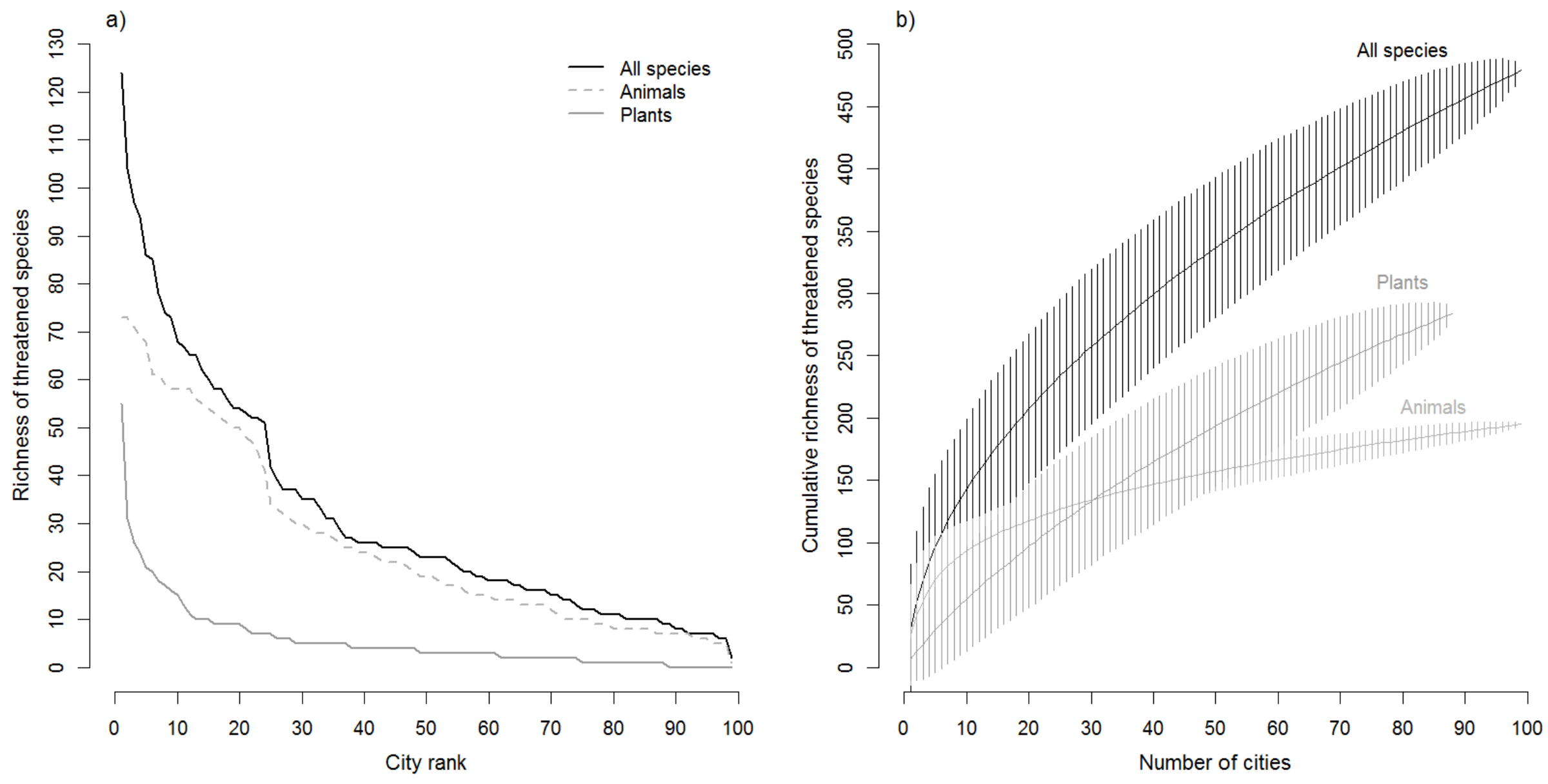
$568 \quad$ Figure 5.

569

a)

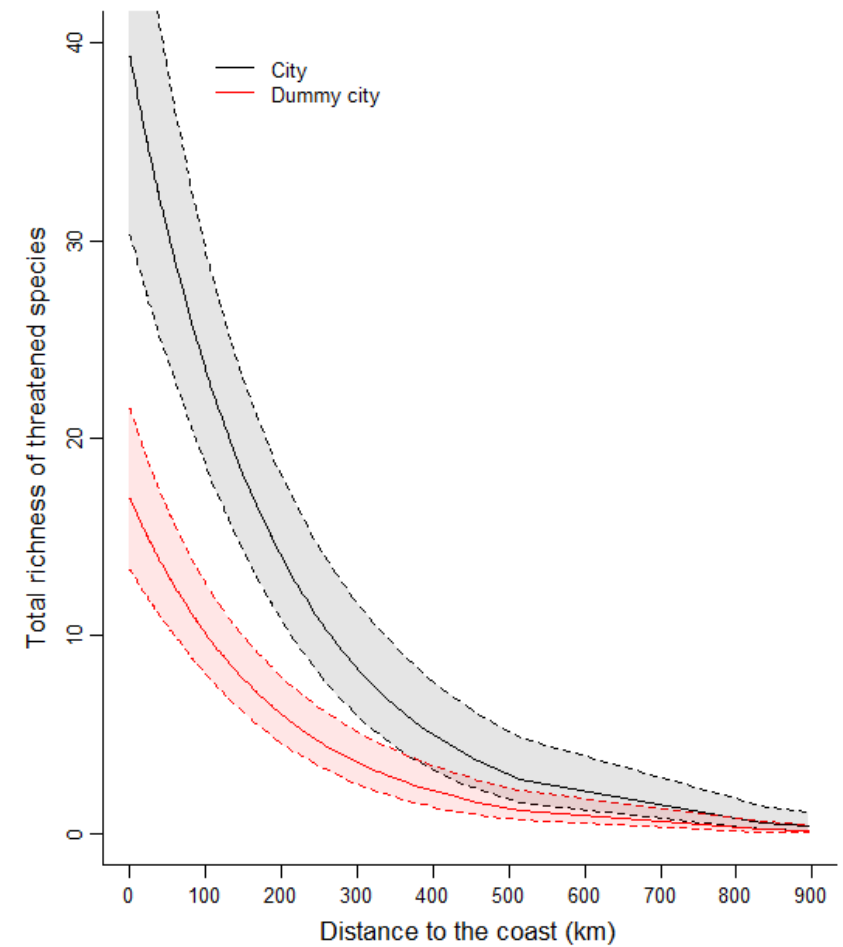

b)

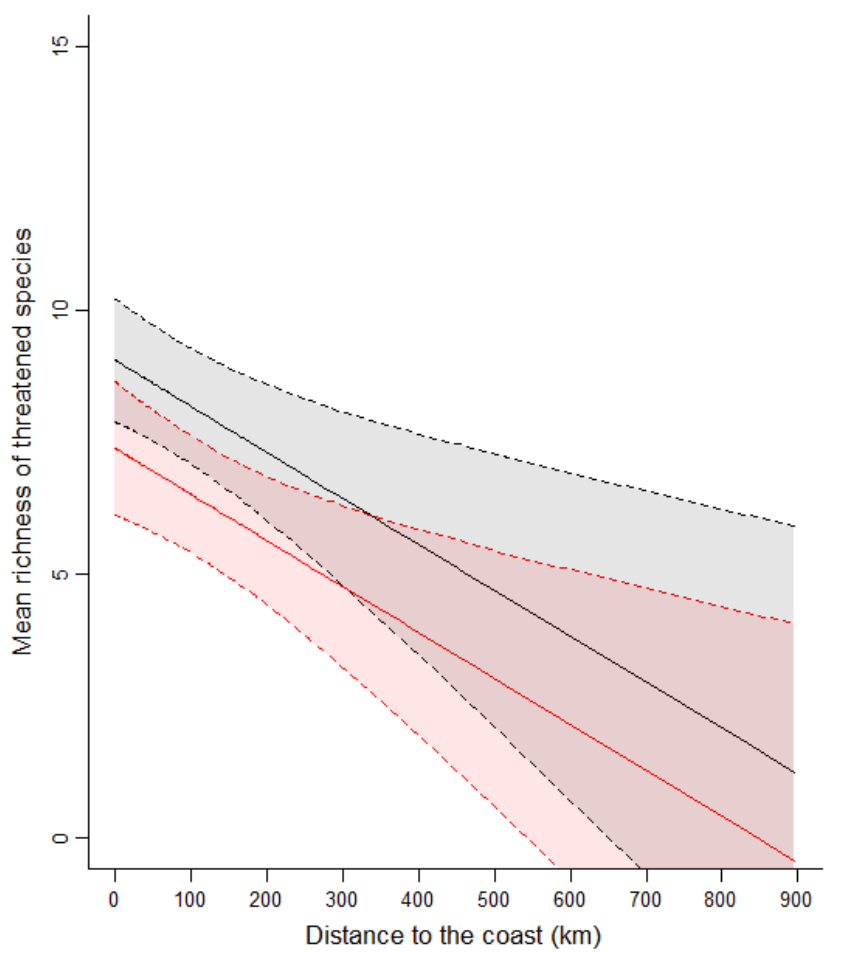

c)

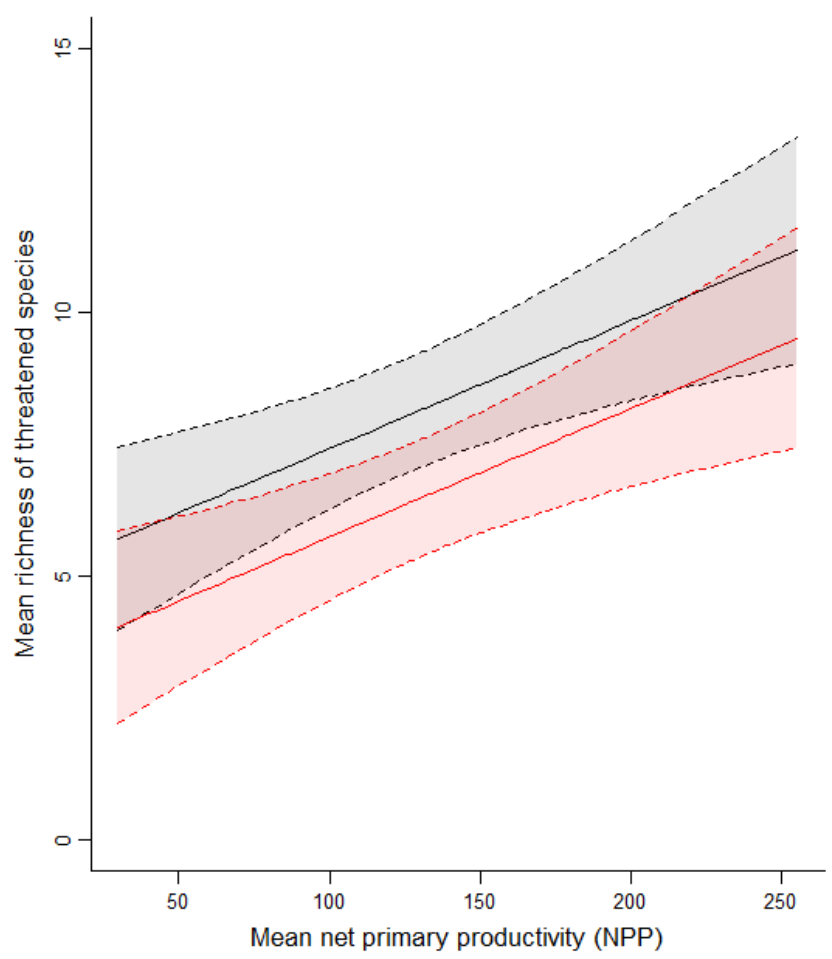




\section{List of Supplementary Materials}

573 Appendix S1: Comparative analysis between known and known and/or likely to occur distributions 574

575 Appendix S2: List of Australian cities, with human population size and total, animal, and plant 576 threatened species richness.

578 Appendix S3: Analysis of differences in threatened species composition between cities including 579 hierarchical cluster analysis of (i) animals and (ii) plants, and maps of mean threatened species 580 community similarity across Australia for (iii) animals and (iv) plants.

582 Appendix S4: Models of (i) total city threatened species richness, and (ii) mean $1 \mathrm{~km}^{2}$ cell 583 threatened species richness for true cities versus dummy cities (non-urban controls). 